\title{
Cooking processes increase bioactive compounds in organic and conventional green beans
}

Giuseppina Pace Pereira Lima, Sergio Marques Costa, Kamila de Almeida Monaco, Maira Rodrigues Uliana, Roberto Morato Fernandez, Camila Renata Correa, Fabio Vianello, Luis Cisneros-Zevallos \& Igor Otavio Minatel

To cite this article: Giuseppina Pace Pereira Lima, Sergio Marques Costa, Kamila de Almeida Monaco, Maira Rodrigues Uliana, Roberto Morato Fernandez, Camila Renata Correa, Fabio Vianello, Luis Cisneros-Zevallos \& Igor Otavio Minatel (2017) Cooking processes increase bioactive compounds in organic and conventional green beans, International Journal of Food Sciences and Nutrition, 68:8, 919-930, DOI: 10.1080/09637486.2017.1324563

To link to this article: https://doi.org/10.1080/09637486.2017.1324563

$$
\text { 曲 Published online: } 15 \text { May } 2017 .
$$

Submit your article to this journal

Џll Article views: 177

View Crossmark data ¿

Citing articles: 4 View citing articles ¿ 


\title{
Cooking processes increase bioactive compounds in organic and conventional green beans
}

\author{
Giuseppina Pace Pereira Lima ${ }^{a}$, Sergio Marques Costa ${ }^{a}$, Kamila de Almeida Monaco ${ }^{a}$, \\ Maira Rodrigues Uliana ${ }^{b}$, Roberto Morato Fernandez ${ }^{c}$, Camila Renata Correa ${ }^{d}$, Fabio Vianello ${ }^{\mathrm{e}}$, \\ Luis Cisneros-Zevallos ${ }^{f}$ and Igor Otavio Minatel ${ }^{\mathrm{a}}$
}

\begin{abstract}
${ }^{a}$ Department of Chemistry and Biochemistry, Institute of Biosciences, São Paulo State University (UNESP), Botucatu, São Paulo, Brazil; bUniversidade do Oeste Paulista (UNOESTE), Presidente Prudente, São Paulo, Brazil; 'Department of Physic and Biophysic, Institute of Biosciences, São Paulo State University (UNESP), Botucatu, São Paulo, Brazil; ${ }^{d}$ Faculty of Medicine, São Paulo State University (UNESP), Botucatu, São Paulo, Brazil; 'Department of Comparative Biomedicine and Food Science, University of Padua (UNIPD), Padua, Italy; fDepartment of Horticultural Sciences, Texas A\&M University, College Station, TX, USA
\end{abstract}

\section{ABSTRACT}

The influence of cooking methods on chlorophyl, carotenoids, polyamines, polyphenols contents and antioxidant capacity were analyzed in organic and conventional green beans. The initial raw material had a higher content of chlorophyl and total phenolics in conventional green beans, whereas organic cultive favored flavonoid content and antioxidant capacity. Polyamines and carotenoids were similar for the two crop systems. After the cooking process, carotenoids ( $\beta$-carotene, lutein and zeaxanthin) increased. Microwave heating favored the enhancement of some polar compounds, whereas pressure cooking favored carotenoids. When we used the estimation of the radical scavenging activity by electron spin resonance (ESR) spectroscopy, a reduction of the DPPH radical signal in the presence of green bean extracts was observed, regardless of the mode of cultivation. The highest reduction of the ESR signal ocurred for microwave cooking in organic and conventional green beans, indicating a higher availability of antioxidants with this type of heat treatment.
ARTICLE HISTORY

Received 9 August 2016

Revised 19 April 2017

Accepted 21 April 2017

\section{KEYWORDS}

Carotenoids; polyamines; total phenolic content; food antioxidant; ESR

\section{Introduction}

Research related to different farming systems has been performed and several studies have aimed to elucidate how the differences in organic and conventional crops can affect plants' primary and secondary metabolism, particularly regarding bioactive compounds (Picchi et al. 2012). Consumers' preference for organic foods, which are free of synthetic pesticides and often richer in antioxidant compounds than conventionally cultivated food, is growing remarkably. The quality of organic foods has been demonstrated in recent years, and a higher content of vitamin $\mathrm{C}$, polyphenols, carotenoids, glucosinolates and other compounds with antioxidant activity than conventional foods (Lima \& Vianello 2011; Rossetto et al. 2015).

Many vegetables, such as green beans (Phaseolus vulgaris $\mathrm{L}$.), are consumed after cooking. The cooking method may influence bioactive compound levels in green beans (De La Cruz-García et al. 1997), primarily those with antioxidant potential. Cooking process is related to the extractibility of matrix compounds (Palermo et al. 2014); however, the thermal processing can induce losses of nutrients due to leaching from the food matrix after heating and can also induce disruption of the cell. Although many studies have shown that organic vegetables contain higher nutrient levels, including antioxidant compounds (polyphenol, carotenoids and polyamines), the effect of cooking on these bioactive compounds in vegetables of organic origin is still inconclusive, and there is a lack of studies reporting which cooking method (boiling or microwave) is ideal to preserve the nutritional quality of vegetables to avoid the loss of antioxidant properties. During organic cultivation, the cultural practices are different from those conventionally grown foods, including the absence of agrochemicals, fertilisation, among others. In many organic crops, the plants tend to have a thicker cell wall, as well as greater lignification of tissues (Park et al. 2013). This characteristic may influence the leaching of chemical compounds present in

CONTACT Giuseppina Pace Pereira Lima gpplima@ibb.unesp.br 를 Department of Chemistry and Biochemistry, Institute of Biosciences, São Paulo State University (UNESP), CP 510, CEP 18 618-970, Botucatu, São Paulo, Brazil 
the cells during cooking, including molecules with antioxidant properties.

Some authors have claimed that there is a loss of antioxidant activity (Zhang \& Hamauzu 2004), whereas other authors have shown an increase or no change in the antioxidant capacity of vegetables after heat treatment (Turkmen et al. 2005). Other reports have shown that domestic cooking methods can increase the polyphenol content in vegetables, including flavonoid and antioxidant capacity, because extractable parts of these molecules are reinforced by plant tissue disruption when subjected to high temperatures (Zhang \& Hamauzu 2004; Turkmen et al. 2005).

Increased or decreased carotenoids levels induced by farming systems (organic or conventional) have been showed. In green beans, the cooking can increase the carotene content from food matrix by softening or disrupting the tissue (De La Cruz-García et al. 1997; Delchier et al. 2012). An opposite result was reported after thermal processing (Zhang \& Hamauzu 2004). However, the clear effect of cooking methods on carotenoids in organic vegetables are still scarce.

Polyamines are related to the scavenging of radical species (Groppa et al. 2007). These molecules also have many biological functions and have been recognised as being involved in cell differentiation and duplication, the regulation and stabilisation of membranes and the metabolism of nucleic acids, in addition to acting as secondary messengers (Larqué et al. 2007). Polyamines, such as spermidine and spermine, may be considered antioxidants because they could modulate the membrane surface charges due to inhibited enzymes and these molecules are related with radical scavengers (LØVaas 1996). Studies have been conducted on the effect of organic food on polyamine levels (Rossetto et al. 2015) and cooking methods (Kalač \& Krausová 2005). However, none of these studies provide strong evidence of cooking effects on the polyamine content in organic foods.

In this way, as the levels of antioxidant compounds can be modified by the crop system, either conventional or organic and in addition to the fact that green beans are usually consumed after thermal processing, we considered to study the influence of different cooking procedures in organic and conventional green beans in the pigments chlorophyl, carotenoids, polyamines, polyphenols contents and antioxidant capacity.

\section{Materials and methods}

\section{Chemicals and plant material}

Folin-Ciocalteu's phenol reagent, sodium carbonate, potassium phosphate, methanol, toluene and acetone were obtained from Vetec/Sigma (Sigma-Aldrich, São Paulo, Brazil); high-performance liquid chromatography (HPLC) grade methanol and HPLC grade acetonitrile was obtained from Tedia (Tedia, Rio de Janeiro, Brazil); others reagents and standards were purchased from Sigma-Aldrich Co (Sigma-Aldrich, St Louis, MO).

Green beans (Phaseolus vulgaris L.) cultivar Itatiba II (Sakata Seed America ${ }^{\circledR}$ ) grown in separated areas of organic and conventional crop systems were acquired from farms in Botucatu, São Paulo, Brazil (latitude $22^{\circ} 53^{\prime} 09^{\prime \prime} \mathrm{S}$, longitude $48^{\circ} 26^{\prime} 42^{\prime \prime} \mathrm{W}$ and altitude $840 \mathrm{~m}$ ). The green beans were obtained from certified organic producers (IBD Certification, Biodynamic Institute, Agricultural and Food Inspections and Certifications, Botucatu/São Paulo, Brazil; this farm converted to this crop management system more than 10 years before the start of this study) and from rural conventional producers present in the same region. The planting was carried out manually in a $32 \mathrm{~m}^{2}$ experimental field consisting of 50 plants per unit with $1.00 \times 0.4 \mathrm{~m}$ spaces between them. Six plants from the central area of each experimental unit were harvested.

During the experiments, mineral fertiliser treatment $\left(120 \mathrm{~g} \mathrm{~m}^{2} \mathrm{~N}\right)$ was applied twice (on the planting day and 15 days after transplantation), and organic fertiliser $\left(8 \mathrm{~kg} \mathrm{~m}^{-2}\right.$ cattle manure) was applied on the planting day. The regional climate is mesothermal, humid subtropical and dry during the winter. Irrigation was carried out twice a day. The samples were harvested 60 days after sowing in the 2014 growing season (dry year). The organic and conventionally grown vegetables were harvested in same physiological and maturation phase. After harvesting, the green bean samples were separated into three packets that contained $100 \mathrm{~g}$ each and were washed with tap water. A portion was processed raw, and the other portions were cooked in individual containers for organic and conventional vegetables. For all treatments, raw and cooked, three green bean packages (samples) were immediately powdered by an analytical mill (IKA, A11, Staufen, Germany) for 3 min with liquid nitrogen and stored at $-80{ }^{\circ} \mathrm{C}$ until analysis. The samples were processed and analyzed in triplicate.

\section{Heat treatment \\ Boiling}

The green beans ( $100 \mathrm{~g} /$ repetition) were added to an aluminum pan ( $2 \mathrm{~L}$ capacity) with water $(200 \mathrm{~mL})$ 
previously heated (boiling), boiled for $10 \mathrm{~min}$ and then drained using a sieve.

\section{Microwave}

The green beans $(100 \mathrm{~g})$ were placed in a Pyrex ${ }^{\circledR}$ dish, and distilled water $(15 \mathrm{~mL})$ was added. The dish was covered with plastic (suitable for a microwave) to prevent water loss (Chuah et al. 2008), and the beans were subjected to cooking for $10 \mathrm{~min}$ in a domestic microwave (Panasonic, $800 \mathrm{~W}$, Manaus, Brazil).

\section{Pressure}

The green beans $(100 \mathrm{~g})$ were placed in a pressure pan (Clock $^{\circledR}, 2$ L capacity, São Bernardo do Campo, Brazil) with water $(100 \mathrm{~mL})$ for heating. After an established pressure was reached, the vegetables were cooked for 10 min (medium heat) and then drained using a sieve.

\section{Pigments content}

\section{Chlorophyll content}

Extraction was performed with $50 \mathrm{mg}$ of fresh and cooked green beans, according to the method described by Sims and Gamon (2002), which was based on the molar absorptivity coefficient of chlorophyl in a buffered solution of acetone. The samples were homogenised for $1 \mathrm{~min}$ in a mini-Turrax (Marconi, São Paulo, Brazil) with $3 \mathrm{~mL}$ of chilled acetone solution containing $20 \%$ Tris- $\mathrm{HCl}(80: 20$, v:v, $\mathrm{pH}$

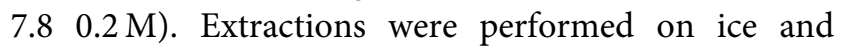
protected from light. Then, the samples were centrifuged at $4000 \mathrm{~g}$ for $5 \mathrm{~min}$ (Hettich, Mikro $220 \mathrm{R}$, DJB Labcare, Newport Pagnell, UK), and the supernatants were immediately read by a UV/VIS spectrophotometer (Pharmacia Biotech Ultrospec 2000, Centerville, VA). The absorbance values of total chlorophyl (663 nm chlorophyl $a$ and $647 \mathrm{~nm}$ chlorophyl $b$ ) were converted into $\mathrm{mg}$ of total chlorophylls per $100 \mathrm{~g}$ fresh weight.

\section{Carotenoids contents}

Total carotenoids and lutein, zeaxanthin and beta carotene were measured by liquid chromatography (HPLC; Muzhingi et al. 2008). The samples (100 mg) were treated with the addition of $100 \mu \mathrm{L}$ $\left(0.095 \mathrm{~mol} \mathrm{~L}^{-1}\right)$ pyrogallol in ethanol, $300 \mu \mathrm{L}$ $\left(0.5 \mathrm{~mol} \mathrm{~L}^{-1}\right) \mathrm{KOH}$ in deionised water and $1 \mathrm{~mL}$ ethanol. The mixture was vortexed and incubated at $37^{\circ} \mathrm{C}$ for $2 \mathrm{~h}$. After incubation, the samples were cooled to room temperature, $1 \mathrm{~mL}$ of water was added, and the mixture was vortexed. The mixture was shaken with
$3 \mathrm{~mL}$ anhydrous ether:hexane (2:1, stabilised with $1 \%$ ethanol v/v), vortexed, and then centrifuged at $800 \mathrm{~g}$ at $4{ }^{\circ} \mathrm{C}$ for $5 \mathrm{~min}$. The upper layer was removed, the extraction was repeated, and the upper layers were combined. $\mathrm{H}_{2} \mathrm{O}(2 \mathrm{~mL})$ was added, the solution was vortexed, and $2 \mathrm{~mL}$ ethanol was added before centrifugation at $800 \mathrm{~g}$ for $5 \mathrm{~min}$. The hexane layer was completely evaporated under $\mathrm{N}_{2}$, and the residue was re-dissolved in $100 \mu \mathrm{L}$ of ethanol, vortexed and sonicated twice for $30 \mathrm{~s}$ and centrifuged at $800 \mathrm{~g}$ at $4{ }^{\circ} \mathrm{C}$ for $2 \mathrm{~min}$. A $30 \mu \mathrm{L}$ aliquot was injected onto the HPLC system (Thermo Scientific, Dionex's Ultimate 3000, Sunnyvale, CA) with a C30 column $(3 \mu \mathrm{m}$, $150 \times 4.6 \mathrm{~mm}$, Wilmington, NC), and carotenoids were monitored at $455 \mathrm{~nm}$ by a photo-diode array detector (Thermo Scientific, Dionex's DAD-3000, Sunnyvale, CA). HPLC mobile phases conditions were the same as those previously described by $\mathrm{Li}$ et al. (2009), consisted of methanol:methyl tert-butyl ether (MBTE):water (95:3:2 by vol with $1.5 \%$ ammonium acetate in water for solvent $\mathrm{A}$ and methanol:MTBE:water (8:90:2 by vol with $1.0 \%$ ammonium acetate in water) for solvent $B$. The mobile phase gradient started at $100 \%$ solvent A; at 21 min linear gradient to $45 \%$ solvent A; 1 min hold at $45 \%$ solvent $\mathrm{A}$; an 11 min linear gradient to $5 \%$ solvent $\mathrm{A}$; at $4 \mathrm{~min}$ hold at $5 \%$ solvent $\mathrm{A} \mathrm{B}$; at 2 min linear gradient back to $100 \%$ solvent $\mathrm{A}$; at $28 \mathrm{~min}$ hold at $100 \%$ solvent $\mathrm{A}$, at a flow rate of $0.4 \mathrm{~mL} \mathrm{~min}^{-1}$ $\left(10^{\circ} \mathrm{C}\right)$. All sample analyzes were conducted in triplicate. We adjusted the results using an internal standard of $\beta$-carotene, lutein and zeaxanthin (SigmaAldrich Co., St. Louis, MO) of $99.98 \%$ purity. Recovery standard average $97 \%$.

\section{Polyamines}

The samples were extracted and isolated according to the procedure of Flores and Galston (1982) modified by Lima et al. (2008). Fresh and cooked $(600 \mathrm{mg})$ green beans were homogenised $(1 \mathrm{~min})$ in a miniTurrax (Marconi, São Paulo, Brazil) with perchloric acid $(5 \%, \mathrm{v} / \mathrm{v})$. After $20 \mathrm{~min}$ of centrifugation $(6000 \mathrm{~g}$, $4{ }^{\circ} \mathrm{C}$, Hettich, Mikro $220 \mathrm{R}$ ), dansyl chloride and saturated sodium carbonate were added to the supernatant. After $16 \mathrm{~h}$, proline was added, and the mixture was kept for $30 \mathrm{~min}$ in the dark, at room temperature. Toluene was utilised to extract polyamines. Finally, sample aliquots were withdrawn and subjected to drying with $\mathrm{N}_{2}$ and resuspended in $3 \mathrm{~mL}$ of HPLC grade acetonitrile. Determination of the PAs content was performed according (Dadáková et al. 2009). The samples $(20 \mu \mathrm{L})$ were injected into a UHPLC system 
(Ultimate 3000 BioRS, Dionex-Thermo Fisher Scientific Inc., Sunnyvale, CA) equipped with a diode array detector (Thermo Scientific, Dionex's DAD3000 , Sunnyvale, CA) set at $225-300 \mathrm{~nm}$, run at a flow rate of $0.7 \mathrm{~mL} \mathrm{~min}^{-1}$ using an Ace $5 \mathrm{C} 18$ (Advanced Chromatography Technologies, Aberdeen, UK) column $(5 \mu \mathrm{m}, 25 \mathrm{~cm} \times 4.6 \mathrm{~mm})$. The chromatographic run gradient scheme performed was established with different proportions of (A) acetonitrile $100 \%$ and (B) acetonitrile $50 \%$ as follows: $0-4 \mathrm{~min}, 40 \% \mathrm{~A}+60 \% \mathrm{~B}$; $4-8 \min , 60 \% \mathrm{~A}+40 \% \mathrm{~B} ; 8-12 \min , 65 \% \mathrm{~A}+35 \% \mathrm{~B}$; $12-15 \min , 85 \% \mathrm{~A}+15 \% \mathrm{~B} ; 15-21 \mathrm{~min}, 95 \% \mathrm{~A}+5 \%$ B; $21-22$ min, $85 \%$ A $+15 \%$ B; 22 min, $75 \%$ A $+25 \%$ B.

The standards were putrescine- $\mathrm{HCl}$, spermine- $\mathrm{HCl}$ and spermidine- $\mathrm{HCl}$, (Sigma-Aldrich Co.). These were dansylated and extracted exactly as for the samples extracts. The identification of the biogenic amines was based on their retention times. The limit of detection (LOD) values were between 0.0025 for putrescine and $0.0029 \mathrm{mg} / \mathrm{L}$ for spermine. The limit of quantification (LOQ) values were 0.005 and $0.098 \mathrm{mg} / \mathrm{L}$.

\section{Total polyphenols}

Polyphenols were analyzed using the Folin-Ciocalteu reagent (Singleton \& Rossi 1965). Approximately $100 \mathrm{mg}$ of fresh and cooked green beans was extracted with $5 \mathrm{~mL}$ of aqueous acetone $(50 \%)$, placed in an ultrasonic bath for $20 \mathrm{~min}$, and subsequently centrifuged for $10 \mathrm{~min}$ (6000g, Hettich, Mikro $220 \mathrm{R}$ ) before the supernatant was collected. The precipitate was re-extracted, and the supernatants were combined. Supernatant aliquots were transferred to tubes with Folin-Ciocalteau and saturated $\mathrm{Na}_{2} \mathrm{CO}_{3}$. All sample analyzes were conducted in triplicate. After $1 \mathrm{~h}$ of reaction (carbonate complete precipitation), the absorbance was measured (Pharmacia Biotech Ultrospec 2000), and the results were expressed in $g$ gallic acid eq. per $100 \mathrm{~g}$ FW.

\section{Total flavonoids}

Extraction was performed according to the method previously described (Alothman et al. 2009). Fresh and cooked green beans $(100 \mathrm{mg})$ were added to acidified methanol (10\%). The samples were placed in an ultrasonic bath for $30 \mathrm{~min}$, and then, aluminum chloride (5\%) was added. Subsequently, the samples were centrifuged at $10,000 \mathrm{~g}$ for $20 \mathrm{~min}$. All sample analyzes were conducted in triplicate. The absorbance of samples was performed at $510 \mathrm{~nm}$, and the results were expressed in $\mathrm{mg}$ rutin eq. per $100 \mathrm{~g}$ FW.

\section{Antioxidant activity (DPPH)}

Antioxidant activity was carried out according to the method proposed by Brand-Williams (Brand-Williams et al. 1995). DPPH solution was prepared with $2 \times 10^{-4} \mathrm{~g} \mathrm{~mL}^{-1}(0.010 \mathrm{mg}$ of DPPH with $50 \mathrm{~mL}$ of ethanol 99.8\%). For extraction, $1 \mathrm{~g}$ of fresh and $1 \mathrm{~g}$ of cooked green beans were diluted with $10 \mathrm{~mL}$ of ethanol $(99.8 \%)$ and centrifuged at $2000 \mathrm{~g}$ at $5^{\circ} \mathrm{C}$ for $10 \mathrm{~min}$ (Hettich Mikro 220 R). All sample analyzes were conducted in triplicate. Readings were performed at $517 \mathrm{~nm}$, and absorbance was converted to the percentage of antioxidant activity using the following equation:

$$
\begin{aligned}
& \% \text { Reduced DPPH }=[\text { (blank absorbance }- \\
& \text { sample absorbance }) \div \text { blank absorbance }] \times 100
\end{aligned}
$$

A calibration curve was prepared with $20,40,80$, 120 and $160 \mu \mathrm{M}$ of Trolox (6-hydroxy-2,5,7,8-tetramethylchroman-2-carboxylic acid), and the results were expressed in $\mu \mathrm{M}$ eq. Trolox per $100 \mathrm{~g}$ FW.

\section{Electron paramagnetic resonance measurements}

Generally, more than one test is used to determine the antioxidant activity of a food, but the results are inconclusive. The optical absorption and magnetic resonance spectroscopies were used in this work to obtain more information about antioxidant activity with the purpose of complementing the results obtained through the method described above.

Electron paramagnetic resonance (EPR) spectra were acquired by an EMX Bruker (band $\mathrm{X}, 9.3 \mathrm{GHz}$ ) spectrometer, equipped with an ER 4102 resonance cavity (Billerica, MA). All measurements were taken at room temperature and the sample analyzes were conducted in triplicate. The samples were prepared as described for the spectrophotometric determination of DPPH (section "Antioxidant activity") and inserted in $40 \mu \mathrm{L}$ quartz capillaries. The microwave power was $12.7 \mathrm{~mW}$, the modulation amplitude and modulation frequency were $1 \mathrm{G}$ and $100 \mathrm{kHz}$, respectively, and the time constant was $81.92 \mathrm{~ms}$. The individual EPR spectrum was measured in $83.88 \mathrm{~s}$, and its integral intensity was determined by the double integration of the EPR lines, which correspond to the area under the curve of the absorption of microwave radiation (Krakowian et al. 2014). DPPH was quantified by the double integration of the EPR signals using WinEPR software by Bruker (Rheinstetten, Germany).

\section{Statistical analysis}

The experimental design was entirely randomised, the Scott-Knott test $(p \leq .05)$ was applied to compare the 
means, and the results are expressed as the mean of nine determinations \pm standard devistion (SD). The software Statistica version 7.0 was utilised (StatSoft Inc., Tulsa, OK).

\section{Results and discussion}

\section{Heat-processing effects on chlorophyl and carotenoids}

The total chlorophyl $(a+b)$ content was higher in raw conventional green beans than in organic beans (Table 1). The boiling and microwave cooking methods induced a significant release of chlorophyl compared with raw samples. However, microwave cooking was more efficient in releasing chlorophyl from the cell matrix, promoting increases of 29 and $45 \%$ in conventional and organic green beans, respectively. De La Cruz-García et al. (1997) showed that microwave cooking induced the chlorophyl extraction of green beans, while the pot, steaming or pressure decrease the chlorophylls levels. Usually, depending on the temperature, chlorophyl losses may occur, decreasing the green coloring, an indicator of quality for certain vegetable products (Turkmen et al. 2006), and increasing the pheophytin content (Sánchez et al. 2014). In this study, cooking under pressure induced losses of chlorophyl in relation to raw samples. This effect was likely due to the high pressure and temperature (Sánchez et al. 2014). However, another effect may be related to the amount of cooking water used. When the microwave cooking was used, the amount of water was small, and a possible leaching effect was reduced, retaining the higher content of this bioactive compound. Thus, regarding chlorophyl content, the consumption of microwaved conventional green beans cooked with a low amount of water can enhance the source of these pigments, which in other studies have been associated to health-promoting properties, including anti-mutagenic, anti-carcinogenic and antiinflammatory functions (Ferruzzi \& Blakeslee 2007).

The analysis of total carotenoids content indicated no difference among raw conventional and organic green beans. All cooking methods employed had a positive effect on the release of carotenoid content. Furthermore, microwave and pressure were more efficient in increasing the total carotenoid content, $\beta$-carotene, lutein and zeaxanthin in conventional green beans than in organic green beans (Table 1). Thus, regarding heat treatments, cooking at temperatures over $100^{\circ} \mathrm{C}$ releases higher carotenoid levels of the matrix, favoring those from raw conventional green beans. Previous reports have shown that different cooking types may lead to this type of behavior (Mulokozi \& Svanberg 2003). Other authors described decreased levels of carotenoids in vegetables after high-temperature cooking. For example, losses of $\beta$-carotene occurred in broccoli, both florets and stems, after boiling and microwaving, whereas lutein levels increased $26.7 \%$ after $5 \mathrm{~min}$ of cooking (Zhang \& Hamauzu 2004). Moreover, a significant increase in lutein was observed in fresh spinach after steaming (Delchier et al. 2012) and in green beans after boiling, steaming, pressure and microwave (De La Cruz-García et al. 1997). These data are consistent with our results, in which we observed a significant increase in lutein after cooking in both organic and conventional green beans. This increase, which usually occurs for carotenoids, has been attributed to a facilitated extraction after heat processing (Colle et al. 2010). In fact, this type of processing promotes a matrix-softening effect, which increases the extractability of phytochemicals and results in a higher concentration with respect to the raw material (Palermo et al. 2014), which was frequently observed for carotenoids (Colle et al. 2010).

In general, our results indicate that the content of both carotenoids and total chlorophyl was higher in cooked green beans from conventional farming than in those cultivated organically. This finding could be attributed to a softer matrix (e.g. cell wall, membranes) in conventional vegetables, facilitating the extraction of some chemical components when compared with organic beans. Generally, in organic farming, due to the absence of chemical treatments, plants are more susceptible to pathogens or other environmental

Table 1. Chlorophyll and carotenoid content in green beans grown on conventional and organic crop system and heat treated.

\begin{tabular}{|c|c|c|c|c|c|c|}
\hline Crop system & Treatments & $\begin{array}{l}\text { Total chlorophyll } \\
\left(\mu \mathrm{g} \mathrm{g}^{-1} \mathrm{FW}\right)\end{array}$ & $\begin{array}{l}\text { Total carotenoids } \\
\left(\mu \mathrm{g} \mathrm{g}^{-1} \mathrm{FW}\right)\end{array}$ & $\begin{array}{c}\beta \text {-Carotene } \\
\left(\mu \mathrm{g} \mathrm{g}^{-1} \mathrm{FW}\right)\end{array}$ & $\begin{array}{c}\text { Lutein } \\
\left(\mu \mathrm{g} \mathrm{g}^{-1} \mathrm{FW}\right)\end{array}$ & $\begin{array}{l}\text { Zeaxanthin } \\
\left(\mu \mathrm{g} \mathrm{g}^{-1} \mathrm{FW}\right)\end{array}$ \\
\hline \multirow[t]{4}{*}{ Conventional } & Raw & $67.11 \pm 5.21^{\mathrm{c}, *}$ & $5.32 \pm 0.25^{c, *}$ & $0.12 \pm 0.11^{\mathrm{d}, *}$ & $5.08 \pm 1.13^{\mathrm{c}, *}$ & $0.12 \pm 0.01^{\mathrm{b}, *}$ \\
\hline & Boiling & $73.51 \pm 3.12^{b}$ & $7.43 \pm 0.53^{b}$ & $0.53 \pm 0.02^{c}$ & $6.71 \pm 1.38^{b}$ & $0.19 \pm 0.10^{b}$ \\
\hline & Microwave & $86.32 \pm 5.51^{a}$ & $13.91 \pm 0.48^{a}$ & $0.82 \pm 0.22^{b}$ & $12.71 \pm 2.31^{\mathrm{a}}$ & $0.32 \pm 0.02^{a}$ \\
\hline & Pressure & $60.42 \pm 1.01^{d}$ & $15.92 \pm 2.87^{\mathrm{a}}$ & $1.36 \pm 0.24^{\mathrm{a}}$ & $12.96 \pm 2.46^{\mathrm{a}}$ & $0.61 \pm 0.02^{\mathrm{a}}$ \\
\hline \multirow[t]{4}{*}{ Organic } & Raw & $35.72 \pm 1.41^{f}$ & $5.71 \pm 0.91^{c}$ & $0.38 \pm 0.14^{c}$ & $5.07 \pm 1.18^{c}$ & $0.25 \pm 0.08^{b}$ \\
\hline & Boiling & $50.01 \pm 1.92^{\mathrm{e}}$ & $9.69 \pm 1.31^{b}$ & $0.60 \pm 0.02^{c}$ & $8.67 \pm 1.59^{b}$ & $0.42 \pm 0.10^{\mathrm{a}}$ \\
\hline & Microwave & $51.83 \pm 2.52^{\mathrm{e}}$ & $7.69 \pm 0.82^{b}$ & $0.56 \pm 0.11^{c}$ & $6.77 \pm 1.75^{b}$ & $0.36 \pm 0.05^{a}$ \\
\hline & Pressure & $32.31 \pm 1.81^{f}$ & $9.94 \pm 1.04^{b}$ & $0.86 \pm 0.13^{b}$ & $8.61 \pm 1.97^{b}$ & $0.48 \pm 0.05^{\mathrm{a}}$ \\
\hline
\end{tabular}

\footnotetext{
*Means followed by the same letters (column) were not statistically significant according to Skott-Knott's test $(p \leq .05), n=9$.
} 
adversities. These vegetables could have a different matrix that is less susceptible to physical damage, which would decrease the release of these compounds from the cell by cooking or heat treatments.

\section{Heat-processing effects on putrescine, spermidine and spermine}

Putrescine levels were not different between organic and conventional raw green beans (Figure 1(A)). All employed heat treatments induced putrescine losses in organic and conventional vegetables, and the losses were higher for the former. The spermidine levels in raw material were the same for both organic and conventional beans; however, after cooking, the content was higher for organic beans (Figure 1(B)). The spermine content was slightly higher in conventional raw green beans than in organic beans. The content decreased for conventional green beans after cooking, and it remained the same for organically grown beans when subjected to heat (Figure $1(\mathrm{C})$ ). The decrease in polyamines after cooking in conventionally grown green beans could be associated to the softer matrix, as described earlier, which not only facilitates the release of these highly polar compounds but also enhances its loss by leaching. In general, spermidine and spermine occurred at higher levels compared with putrescine for both raw green bean crop systems.


Figure 1. Polyamines: (A) putrescine, (B) spermidine and (C) spermine in green beans grown under conventional and organic crop system and heat treated. Means \pm standard deviation, $n=9$ (gray bars: conventional cultive; black bars: organic cultive). 
Previous studies comparing polyamine levels in organic and conventional vegetables showed that organic ones appeared to contain higher levels of these amines (Lima et al. 2008). These substances are directly correlated with juvenility; in organic plants, a larger shelf life can be attributed to these higher polyamine levels. The highest spermidine and spermine levels found may be an important source of these substances, which can act as antioxidants (Toro-Funes et al. 2013), as free radical scavengers and/or in the chelation of metals (Groppa et al. 2007). Therefore, the consumption of organic or conventionally cooked green beans can be a good source of spermidine and spermine and potential antioxidants, whereas a higher spermine content may be a positive aspect; according to Toro-Funes et al. (2013), this tetramine (higher levels in cooked organic green beans) has higher antioxidant power because it possesses additional amino groups (Toro-Funes et al. 2013).

\section{Heat-processing effects on polyphenols}

The total phenolic content was higher in raw conventionally grown green beans than in organically grown beans (Table 2). However, the total flavonoid and antioxidant activity showed the opposite effect of organics presenting higher levels.

All cooking treatments employed induced the reduction of phenolic compounds in conventional vegetables, whereas the content remained almost the same for organic beans. It is likely that the physical process may have induced combined heat degradation and leaching effects, the former possibly due to a less resistant cell wall in conventionally grown beans. Polyphenol losses were also observed by other authors and were attributed to heat degradation (Randhir et al. 2008; Sultana et al. 2008). An increase in the polyphenol content in green beans after cooking was also described (Turkmen et al. 2005). In the present study, organic green beans showed also an increase in phenolics after pressure cooking, likely favoring a softening of the matrix but with a lower effect on leaching (Table 2).

In general, heat treatments induced a decrease in flavonoid content in both conventional and organic beans, with the exception of microwave heating in the former samples (Table 2). This effect of reduced content after heating and that described in total phenolic compounds can likely be attributed to the matrix softening and the release of compounds plus the additional effects of leaching and compound degradation due to the heating process. Other studies have also shown a reduction of polyphenols, such as in carrots after cooking with water (Sultana et al. 2008). In the present study, microwave treatment induced an increase in flavonoids in conventional green beans, possibly due to a combination of factors: a higher softening of the matrix, a lower solubilisation of these polyphenols (a polar to non-polar behavior because only $15 \mathrm{~mL}$ of water was used for $100 \mathrm{~g}$ of green beans) favoring decreased leaching and a lower degradation effect. However, the results observed in organic green beans may be attributed to differentiated cell structure in response of the culture conditions. Differences regarding thickening and lignification of the cell wall due to elicitors (Park et al. 2013) (a form of plant defense against pathogens, due to the absence of agrochemicals) might contribute to the retention and difficulty of extracting these compounds from organic green beans. The exact influence of each factor should be the focus of future research to determine the specifics of all kinetics involved. Accordingly, our results suggest that to obtain and maintain the content of flavonoids, the use of microwaves could be recommended. There is considerable evidence of flavonoids used in the diet and its relation to the reduction of disease, such as coronary artery disease, and cancer (García-Lafuente et al. 2009).

\section{Heat-processing effects on antioxidant activity}

Sample antioxidant activity was determined by the DPPH method (see "Materials and methods" section)

Table 2. Total polyphenols, flavonoids and antioxidant activity in green beans grown on conventional and organic crop system and heat treated.

\begin{tabular}{|c|c|c|c|c|}
\hline Crop system & Treatments & $\begin{array}{l}\text { Total polyphenols } \\
\text { (g eq. ac. Galic } 100 \mathrm{~g}^{-1} \mathrm{FW} \text { ) }\end{array}$ & $\begin{array}{l}\text { Total flavonoids } \\
\text { (mg eq. ac. Rutin } 100 \mathrm{~g}^{-1} \mathrm{FW} \text { ) }\end{array}$ & $\begin{array}{c}\text { DPPH ( } \mu \text { Meq. } \\
\left.\text { TROLOX } 100 \mathrm{~g}^{-1} \mathrm{FW}\right) \\
\end{array}$ \\
\hline \multirow[t]{3}{*}{ Conventional } & Raw & $2.03 \pm 0.14^{\mathrm{a}, *}$ & $45.82 \pm 5.36^{\mathrm{d}, *}$ & $9.43 \pm 0.39^{\mathrm{e}, *}$ \\
\hline & Microwave & $0.97 \pm 0.12^{c}$ & $101.99 \pm 3.38^{a}$ & $40.55 \pm 2.06^{a}$ \\
\hline & Pressure & $1.35 \pm 0.06^{b}$ & $21.46 \pm 1.45^{\mathrm{e}}$ & $16.66 \pm 1.47^{d}$ \\
\hline \multirow[t]{2}{*}{ Organic } & Raw & $1.03 \pm 0.07^{c}$ & $71.48 \pm 1.15^{b}$ & $20.07 \pm 2.60^{d}$ \\
\hline & Pressure & $1.39 \pm 0.10^{b}$ & $38.61 \pm 1.68^{d}$ & $30.31 \pm 0.72^{b}$ \\
\hline
\end{tabular}

*Means followed by the same letters (column) were not statistically significant according to Skott-Knott's test ( $p \leq .05), n=9$. 
and was found to be higher in raw organic green beans than in conventional green beans following a trend similar to that of flavonoids (Table 2). After thermal processing, notably, there was an increase in antioxidant activity for both organic and conventional green beans. This increase did not follow the pattern observed for total phenolics for flavonoids, but it did follow the pattern increase observed for chlorophyl and carotenoids (Table 2). Accordingly, our results suggest that the increase observed in antioxidant activity after cooking would be the result of a combined release of compounds, including polyphenols, carotenoids, chlorophyl and possibly other compounds not analyzed in this study. Turkmen et al. (2005) observed in several vegetables, including green beans, that cooking induced an increase in total antioxidant activity. The authors attributed this effect to the denaturation of peroxidases, oxidising enzymes, which use phenolic compounds as substrates. By contrast, a decrease in antioxidant activity after thermal processing has been described in broccoli (Zhang \& Hamauzu 2004) and green beans (Jiménez-Monreal et al. 2009).

Once again, we observe that microwave heating favors the enhancement of antioxidant activity, which can be the result of a combined effect of matrix softening releasing the active compounds and a decreased leaching and degradation process. This finding could be due to the specificity of the energy deposition mechanism by microwave treatment on samples. The absorption of microwaves depends on the polarity of the target molecules. Polar molecules, such as acids, esters, alcohols, amines and carbonyl compounds (and obviously water), rapidly absorb microwave energy, whereas non-polar molecules, such as hydrocarbons, absorb very low amounts of energy by microwave (Gedye et al. 1988). The heat generated in the sample, due to the vibration of polar molecules, reduces heat loss to the outside environment, in contrast to other cooking processes, where heat transfer occurs from a hot solid to cold sample material.

\section{Heat-processing effects on antioxidant activity by electron spin resonance}

Figure 2 shows the optical absorption spectra of a solution of pure $1.7 \times 10^{-5} \mathrm{~g} \mathrm{~mL}^{-1} \mathrm{DPPH}$ in ethanol and after the addition of extracts of conventionally and organically grown green beans treated with different forms of cooking. These spectra represent the average of three measurements, and line thickness represents the standard deviation. DPPH analysis showed a strong absorption band at $517 \mathrm{~nm}$ due to its odd electron, and solutions appeared in a deep violet color.
At this wavelength, small differences between the absorption spectra from conventional and organic samples were observed, with organic samples presenting a slightly larger DPPH signal reduction than conventional samples, except in those cooked by a microwave, which presented an inverse behavior. When different types of cooking were compared, the spectra of the extracts showed a gradual change in shape, depending on the heat treatment applied. The addition of raw green bean extracts led to a reduction of the DPPH signal, resulting from the chemical reaction between unpaired DPPH electrons and antioxidant molecules in the extract. When thermally processed samples were compared, a peak at $414 \mathrm{~nm}$ appeared in the optical absorption spectra, which was more evident in samples treated by pressure and microwave cooking. This change in the spectrum is the result of the superposition of the DPPH signal, with that of other molecules absorbing at $414 \mathrm{~nm}$. The observed signal at $414 \mathrm{~nm}$ can be related to the increasing availability of carotenoids (Sims \& Gamon 2002) and flavonoids (Jovanovic et al. 1994) in the extract with increasing temperature because this wavelength belongs to the absorption band of these molecules. However, comparing this result with the result presented in Tables 1 and 2, cooking by microwave heating resulted in the more efficient release of carotenoids; it can be seen that this thermal processing induced increasing levels of carotenoids, independently of the type of crop.

Moreover, the signal at $414 \mathrm{~nm}$ has an inverse relationship with the typical DPPH band at $517 \mathrm{~nm}$. Figure $3(A, B)$ illustrates this inverse relationship in the absorption spectra of extract obtained after different types of cooking of conventionally and organically grown green beans. The DPPH absorbance value at $517 \mathrm{~nm}$ decreased to $68 \%$ in the presence of conventionally grown raw green bean extracts. With boiling or pressure-cooked samples, the absorbance value at $517 \mathrm{~nm}$ was lower (48.9\%), whereas extracts of green beans treated by microwaving showed an absorbance value of $10.9 \%$ with respect to the initial DPPH absorbance (Figure 3(A)). For the organic crop system (Figure 3(B)), the DPPH signal at $517 \mathrm{~nm}$ reduced to $57.6 \%$ for raw green bean extract, $45.5 \%$ for boiling and pressure cooking, and $25 \%$ for microwave treatment with respect to the initial DPPH absorbance.

The antioxidant activity of the extracts was calculated according to equation showed in antioxidant activity (see "Materials and methods" section). The extract of conventionally grown raw green bean led to the inhibition of the DPPH signal of $39.2 \%$, followed by boiling and pressure-treated samples $(51.2 \%)$, and 


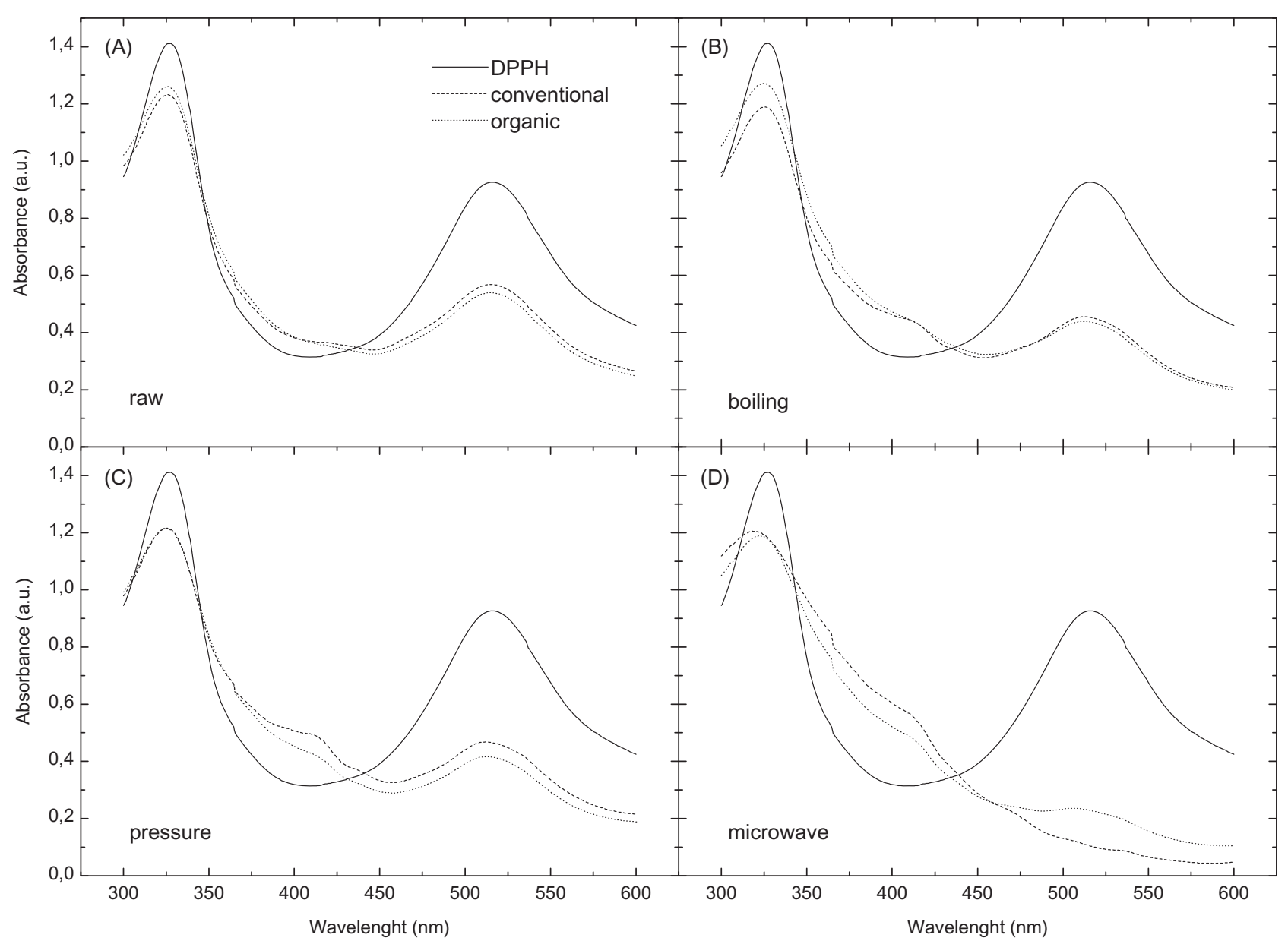

Figure 2. Optical spectra of DPPH in the absence (black line) and in the presence of extracts of green beans coming from conventional (red line) and organic (green line) crop systems and different heat treatments. (A) Raw; (B) boiling; (C) pressure and (D) microwave. Spectra represent the average of nine measurements and line thickness the standard deviation.

microwave cooking gave a DPPH reduction of $89.1 \%$, indicating the highest antioxidant activity. For organically grown green beans, the inhibition of the DPPH signal was $42.4 \%$ for raw-, $54.5 \%$ for both boilingand pressure-, and $75 \%$ for microwave-treated samples. Comparing both crop systems, the inhibition of the DPPH signal was slightly higher for organic crops, except for microwave-treated samples. This result is in agreement with the results presented in Table 2, which shows the highest total flavonoid content in conventional green beans after microwave cooking. Because there was an inverse relationship between the absorbance presented at $517 \mathrm{~nm}$ and that at $414 \mathrm{~nm}$, the inhibition of DPPH signal could also be related to the increase in the flavonoid amount in the sample.

The estimation of the radical scavenging activity of various vegetables has been demonstrated in the recent literature by electron spin resonance (ESR) spectroscopy (Krakowian et al. 2014), including differentiation between organic and conventional cultivation (Tobolková et al. 2014). Therefore, in this work, the antioxidant activity of green bean extracts on DPPH reduction was also assessed by ESR spectroscopy. In the case of free radicals, such as DPPH, when immersed in a strong magnetic field, electromagnetic radiation in the microwave range promotes the spin transition of unpaired electrons between different energy levels (Regulla \& Deffner 1982). This technique is not influenced by the optical properties of the sample, and it gives information regarding free radical concentration in the tested solutions and according to Polak and Bartoszek (2015), this technique is appropriate because it is the only analytical method available to specifically detect free radicals. In study comparing antioxidative capacities of fruit juices, drinks and nectars, it was showed that ESR spectroscopy is more adequate than UV-vis spectroscopy for determining antioxidant capactity with the use of the DPPH free radical (Bartoszek \& Polak 2016). In the present case, DPPH is a stable free radical, which can be easily detected by ESR spectroscopy, and any antioxidant compound in the sample will lead to $\mathrm{DPHH}$ 
radical reduction and to the disappearance of its ESR signal (Anissi et al. 2014).

A reduction of the DPPH radical signal in the presence of green bean extracts is observed, regardless of the mode of cultivation. Moreover, a marked decrease in the DPPH signal in the presence of microwavetreated green beans was observed. The organic planting method appeared to promote slightly higher differences in the reduction of the DPPH signal compared with conventional planting. The only exception was for microwave-treated green beans, which showed a higher reduction for conventional crops, as observed by optical absorption.

For both crop systems, in the thermally treated samples, there was a larger reduction of the DPPH ESR

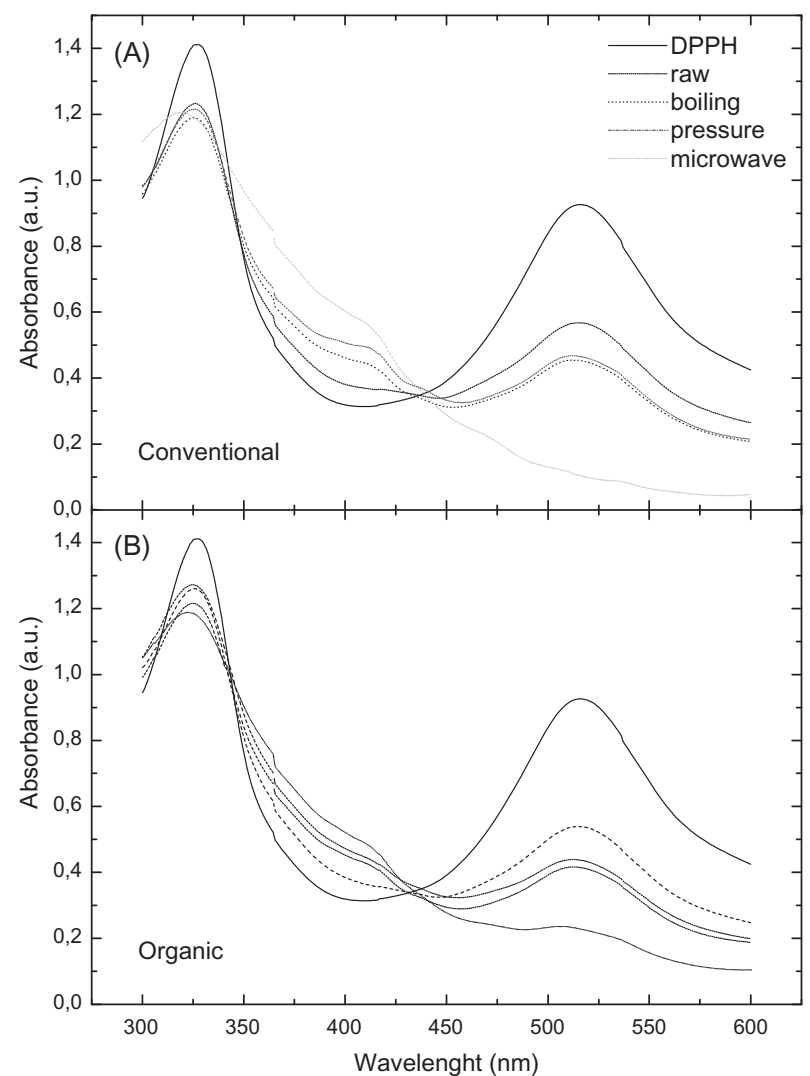

Figure 3. Optical absorption spectra of DPPH in the absence and in the presence of extracts of conventionally $(A)$ and organically (B) grown green beans treated by different heat treatments. Spectra represent the average of nine measurements and line thickness the standard deviation. signal. As discussed earlier (see Tables 1 and 2), this can be attributed to the increased availability of antioxidant molecules upon thermal treatment. The reduction of the ESR signal was similar after boiling and pressure treatments for the conventional planting method. However, in the organically treated green bean extract, the reduction of the ESR signal was higher for pressure treatment than for boiling treatment. The highest reduction of the ESR signal was observed for microwave cooking, indicating a higher availability of antioxidants with this type of heat treatment.

Small differences between the DPPH signals from conventional and organic samples were observed. Organic samples presented a slightly larger DPPH signal reduction than conventional samples, except in those cooked by microwaves, which presented an inverse behavior. Comparing the percentages in Table 3 with those obtained by optical absorption, we observed an increasing of the percentages for this last technique. These larger values could be related to the superposition of the absorption bands of DPPH and antioxidant molecules such as carotenoids and flavonoids (Jovanovic et al. 1994; Sims \& Gamon 2002).

\section{Conclusion}

In the present study, there was no defined trend in initial bioactive compound content or crop systems used for green bean cultivation. Conventional beans favored chlorophyl and total phenolics, and organics favored flavonoids and antioxidant activity. Carotenoid and polyamines were almost similar in the two crop systems. However, the results showed a trend of a higher content of non-polar compounds, such as carotenoids, in conventional crops than in organic crops under different heating processes. This effect was not observed in more polar compounds, such as polyphenols, polyamines and chlorophylls, in which the content decreased or remained the same independent of crop system. It is likely that susceptibility of conventional crops matrix to heating (matrix softening) favored the extractability of non-polar compounds, and due to their non-polarity, nature these were retained within the matrix with negligible

Table 3. Double integration values of DPPH assays by ESR spectra in the absence and in the presence of extracts of conventionally and organically grown green beans and their percentage of signal reduction ${ }^{\mathrm{a}}$.

\begin{tabular}{|c|c|c|c|c|c|}
\hline & DPPH & Raw & Boiling & Microwave & Pressure \\
\hline Double integration value Reduction of DPPH (\%) for conventional system & $7.22 \times 10^{6}$ & $4.57 \times 10^{6}$ & $3.83 \times 10^{6}$ & $1.17 \times 10^{6}$ & $3.97 \times 10^{6}$ \\
\hline & & 36.7 & 46.9 & 83.8 & 45.0 \\
\hline Double integration value Reduction of DPPH (\%) for organic system & $7.22 \times 10^{6}$ & $\begin{array}{l}4.52 \times 10^{6} \\
37.4\end{array}$ & $\begin{array}{l}3.65 \times 10^{6} \\
49.4\end{array}$ & $\begin{array}{l}2.03 \times 10^{6} \\
71.9\end{array}$ & $\begin{array}{l}3.19 \times 10^{6} \\
55.8\end{array}$ \\
\hline
\end{tabular}

${ }^{a}$ The percentage of signal reduction was calculated similarly to equation in "Material and methods" section, using the double integration value of ESR spectrum. 
leaching and degradation effects. On the other side, this same matrix-softening effect also released polar compounds; however, due to their polar nature, these compounds were diffused out by leaching, or their content decreased due to degradation. In general, cooking green beans by microwaving was more effective than other processes in promoting the availability of antioxidants measured by the DPPH assay. However, further studies are needed to understand how microwave heating and other heating processes affect matrix softening and the release of active compounds, the leaching process and degradation effects. These combined factors ultimately defined the concentration of compounds and antioxidant levels after the heating process of conventional or organic crops. These results will help establish parameters for consumers and food scientists to compare the nutritional qualities of vegetables produced in organic or conventional farming. Furthermore, the demand for organic food products is steadily increasing, and assessing the modifications on bioactive compounds, induced by domestic cooking methods, is an important step to obtain expected healthier nutrition.

\section{Disclosure statement}

No potential conflict of interest was reported by the authors.

\section{Funding}

This work was funded by São Paulo Research Foundation (FAPESP) (2013/05644-3), National Council for Scientific and Technological Development (CNPq) (306151/2012-0) and Coordination for the Improvement of Higher Level -or Education- Personnel (CAPES) (02441/09-8 and 478375/10-7).

\section{References}

Alothman M, Bhat R, Karim AA. 2009. Antioxidant capacity and phenolic content of selected tropical fruits from Malaysia, extracted with different solvents. Food Chem. 115:785-788.

Anissi J, El Hassouni M, Ouardaoui A, Sendide K. 2014. A comparative study of the antioxidant scavenging activity of green tea, black tea and coffee extracts: a kinetic approach. Food Chem. 150:438-447.

Bartoszek M, Polak J. 2016. A comparison of antioxidative capacities of fruit juices, drinks and nectars, as determined by EPR and UV-vis spectroscopies. Spectrochim Acta Mol Biomol Spectrosc. 153:546-549.

Brand-Williams W, Cuvelier ME, Berset C. 1995. Use of a free radical method to evaluate antioxidant activity. Food Sci Technol. 28:25-30.
Chuah AM, Lee Y-C, Yamaguchi T, Takamura H, Yin L-J, Matoba T. 2008. Effect of cooking on the antioxidant properties of coloured peppers. Food Chem. 111:20-28.

Colle I, Van Buggenhout S, Van Loey A, Hendrickx M. 2010. High pressure homogenization followed by thermal processing of tomato pulp: Influence on microstructure and lycopene in vitro bioaccessibility. Food Res Int. 43:2193-2200.

Dadáková E, Kř́žžek M, Pelikánová T. 2009. Determination of biogenic amines in foods using ultra-performance liquid chromatography (UPLC). Food Chem. 116:365-370.

De La Cruz-García C, González-Castro MJ, Oruña-Concha MJ, López-Hernández J, Simal-Lozano JÁ, SimalGandarra J. 1997. The effects of various culinary treatments on the pigment content of green beans (Phaseolus vulgaris L.). Food Res Intern. 30:787-791.

Delchier N, Reich M, Renard CMGC. 2012. Impact of cooking methods on folates, ascorbic acid and lutein in green beans (Phaseolus vulgaris) and spinach (Spinacea oleracea). Food Sci Technol. 49:197-201.

Ferruzzi MG, Blakeslee J. 2007. Digestion, absorption, and cancer preventative activity of dietary chlorophyll derivatives. Nutr Res. 27:1-12.

Flores H, Galston A. 1982. Analysis of polyamines in higher plants by high performance liquid chromatography. Plant Physiol. 69:701-706.

García-Lafuente A, Guillamón E, Villares A, Rostagno MA, Martínez JA. 2009. Flavonoids as anti-inflammatory agents: implications in cancer and cardiovascular disease. Inflamm Res. 58:537-552.

Gedye RN, Smith FE, Westaway KC. 1988. The rapid synthesis of organic compounds in microwave ovens. Can J Chem. 66:17-26.

Groppa MD, Tomaro ML, Benavides MP. 2007. Polyamines and heavy metal stress: the antioxidant behavior of spermine in cadmium- and copper-treated wheat leaves. Biometals. 20:185-195.

Jiménez-Monreal AM, García-Diz L, Martínez-Tomé M, Mariscal M, Murcia MA. 2009. Influence of cooking methods on antioxidant activity of vegetables. J Food Sci. 74:H97-H103.

Jovanovic SV, Steenken S, Tosic M, Marjanovic B, Simic MG. 1994. Flavonoids as antioxidants. J Am Chem Soc. 116:4846-4851.

Kalac P, Krausová P. 2005. A review of dietary polyamines: Formation, implications for growth and health and occurrence in foods. Food Chem. 90:219-230.

Krakowian D, Skiba D, Kudelski A, Pilawa B, Ramos P, Adamczyk J, Pawłowska-Góral K. 2014. Application of EPR spectroscopy to the examination of pro-oxidant activity of coffee. Food Chem. 151:110-119.

Larqué E, Sabater-Molina M, Zamora S. 2007. Biological significance of dietary polyamines. Nutrition. 23:87-95.

Li L, Aldini G, Carini M, Chen C-YYO, Chun H-KK, Cho S-MM, Park K-MM, Correa CR, Russella RM, Blumberga JB, Yeum K-J. 2009. Characterisation, extraction efficiency, stability and antioxidant activity of phytonutrients in Angelica keiskei. Food Chem. 115:227-232.

Lima GPP, da Rocha SA, Takaki M, Ramos PRR, Ono EO. 2008. Comparison of polyamine, phenol and flavonoid contents in plants grown under conventional and organic methods. Int J Food Sci Technol. 43:1838-1843. 
Lima GPP, Vianello F. 2011. Review on the main differences between organic and conventional plant-based foods. Int J Food Sci Technol. 46:1-13.

LØVaas E. 1996. Antioxidative and metal-chelating effects of polyamines. Adv Pharmacol. 38:119-149.

Mulokozi G, Svanberg U. 2003. Effect of traditional open sun-drying and solar cabinet drying on carotene content and vitamin A activity of green leafy vegetables. Plant Foods Hum Nutr. 58:1-15.

Muzhingi T, Yeum K-J, Russell RM, Johnson EJ, Qin J, Tang G. 2008. Determination of carotenoids in yellow maize, the effects of saponification and food preparations. Int J Vitam Nutr Res. 78:112-120.

Palermo M, Pellegrini N, Fogliano V. 2014. The effect of cooking on the phytochemical content of vegetables. J Sci Food Agric. 94:1057-1070.

Park YS, Im MH, Ham K, Kang S, Park Y, Namiesnik J, Leontowicz H, Leontowicz M, Katrich E, Gorinstein S. 2013. Nutritional and pharmaceutical properties of bioactive compounds in organic and conventional growing kiwifruit. Plants Foods Hum Nutr. 68:57-64.

Picchi V, Migliori C, Lo Scalzo R, Campanelli G, Ferrari V, Di Cesare LF. 2012. Phytochemical content in organic and conventionally grown Italian cauliflower. Food Chem. 130:501-509.

Polak J, Bartoszek M. 2015. The study of antioxidant capacity of varieties of nalewka, a traditional Polish fruit liqueur, using EPR, NMR and UV-vis spectroscopy. J Food Compos Anal. 40:114-119.

Randhir R, Kwon Y-I, Shetty K. 2008. Effect of thermal processing on phenolics, antioxidant activity and healthrelevant functionality of select grain sprouts and seedlings. Innov Food Sci Emerg Technol. 9:355-364.

Regulla DF, Deffner U. 1982. Dosimetry by ESR spectroscopy of alanine. Int J Appl Radiat Isot. 33:1101-1114.

Rossetto MRM, Vianello F, Saeki MJ, Lima GPP. 2015. Polyamines in conventional and organic vegetables exposed to exogenous ethylene. Food Chem. 188:218-224.

Sánchez C, Baranda AB, Martínez de Marañón I. 2014. The effect of high pressure and high temperature processing on carotenoids and chlorophylls content in some vegetables. Food Chem. 163:37-45.

Sims DA, Gamon JA. 2002. Relationships between leaf pigment content and spectral reflectance across a wide range of species, leaf structures and developmental stages. Remote Sens Environ. 81:337-354.

Singleton VL, Rossi JAJ. 1965. Colorimetry of total phenolics with phosphomolybdic-phosphotungstic acid reagents. Am J Enol Vitic. 16:144-158.

Sultana B, Anwar F, Iqbal S. 2008. Effect of different cooking methods on the antioxidant activity of some vegetables from Pakistan. Int J Food Sci Technol. 43:560-567.

Tobolková B, Polovka M, Belajová E. 2014. Possibilities of organic and conventional wines differentiation on the basis of multivariate analysis of their characteristics (EPR, UV-Vis, HPLC and AAS study). Eur Food Res Technol. 239:441-451.

Toro-Funes N, Bosch-Fusté J, Veciana-Nogués MT, Izquierdo-Pulido M, Vidal-Carou MC. 2013. In vitro antioxidant activity of dietary polyamines. Food Res Int. 51:141-147.

Turkmen N, Sari F, Velioglu Y. 2005. The effect of cooking methods on total phenolics and antioxidant activity of selected green vegetables. Food Chem. 93:713-718.

Turkmen N, Sari F, Velioglu YS. 2006. Effects of extraction solvents on concentration and antioxidant activity of black and black mate tea polyphenols determined by ferrous tartrate and Folin-Ciocalteu methods. Food Chem. 99:835-841.

Zhang D, Hamauzu Y. 2004. Phenolics, ascorbic acid, carotenoids and antioxidant activity of broccoli and their changes during conventional and microwave cooking. Food Chem. 88:503-509. 